thành phần chế nhày trong phân tích vi thể. Chúng tôi định nghĩa nhóm này là nhóm có thành phần chế nhày và không nhận thấy sự khác biệt có ý nghĩa thống kê về thời gian sống thêm sau mổ $(p=0.551)$. Do đó, có thể nói rằng thể mô bệnh học ung thư biểu mô chế nhày không được coi là yếu tố tiên lượng độc lập đối với ung thư dạ dày. Nguyên nhần dẫn đến tiên lượng xấu của nhóm chế nhày có thể do tỷ lệ giai đoạn tiến triển ở thời điểm chẩn đoán cao hơn với các đặc tính sinh học hay mức độ xâm lấn.

\section{KẾT LUÂN}

Qua nghiên cứu 302 trường hợp ung thư biểu mô tuyến dạ dày được phẫu thuật triệt để tại Bệnh viện Hữu nghị Việt Đức, chúng tôi nhận thấy rằng thời gian sống thêm trung bình là 43.4 tháng với tỷ lệ sống sau 1,3 , và 5 năm tương ứng là $97 \%, 77 \%$ và $71 \%$. Giai đoạn bệnh, số hạch di căn, mức độ biệt hóa và xâm lấn mạch, thần kinh là các yếu tố nguy cơ đối với tỷ lệ sống thêm sau mổ trong khi sự có mặt của thành phần chế nhày và phân loại của Lauren không mang ý nghĩa tiên lượng đối với tỷ lệ này.

\section{TÀI LIẸU THAM KHẢO}

1. Howlader $N$, Noone $A M$, Krapcho $M$ và cộng sứ. (2020). SEER Cancer Statistics Review, 19752017 based on November 2019 SEER data submission, posted to the SEER web site, April 2020, https://seer.cancer.gov/csr/1975_2017/.
National Cancer Institute.

2. H. Katai, T. Ishikawa, K. Akazawa và cộng sư. (2018). Five-year survival analysis of surgically resected gastric cancer cases in Japan: a retrospective analysis of more than 100,000 patients from the nationwide registry of the Japanese Gastric Cancer Association (2001-2007). Gastric Cancer, 21(1), 144-54.

3. Đố Đức Vân (1993). Điêu trị phẫu thuâtt ung thư da dày tại Bệnh viện Việt Đức (1970-1992). Y học Việt Nam, (7), 45-50.

4. Trịnh Hồng Sơn, Nguyễn Quang Nghĩa (1998). Đánh giá thời gian sống thêm sau mổ ung thư da dày bằng phương pháp Kaplan Meier. Y học Thực hành, 7, 44-48.

5. S. N. Hochwald, S. Kim, D. S. Klimstra và cộng sự. (2000). Analysis of 154 actual five-year survivors of gastric cancer. J Gastrointest Surg, 4(5), 520-5.

6. T. Ichikura, S. Tomimatsu, Y. Okusa và cộng sư. (1993). Comparison of the prognostic significance between the number of metastatic lymph nodes and nodal stage based on their location in patients with gastric cancer. J Clin Oncol, 11(10), 1894-900.

7. Trinhh Hồng Sơn, Đố Đức Vân (1997). Đặc điểm di căn hạch bạch huyết của ung thư dạ dày. Y học Thực hành, 11, 11-15.

8. F. Feng, J. Liu, F. Wang và cộng sự. (2018). Prognostic value of differentiation status in gastric cancer. BMC Cancer, 18(1), 865.

9. B. J. Dicken, K. Graham, S. M. Hamilton và cộng sự. (2006). Lymphovascular invasion is associated with poor survival in gastric cancer: an application of gene-expression and tissue array techniques. Ann Surg, 243(1), 64-73.

\title{
NGHIÊN CỨU THỰC TRẠG SỬ DỤNG KHÁNG SINH TRONG ĐÎ̀UU TRI VIÊM PHỔI MẮC PHẢI CộNG ĐỒNG TẠI BỆNH VIỆN HỮU NGHỊ ĐA KHOA NGHỆ AN
}

\section{TÓM TẮT}

Mục tiêu: Khảo sát tình hình sử dụng kháng sinh trong điêu trị viêm phổi mắc phải ở cộng đồng tại Bệnh viện Hữu Nghị Đa Khoa Nghệ Añ năm 2021. Phương pháp: Nghiên cứu mô tả cắt ngang được thực trên 80 bệnh nhân viêm phổi mắc phái cộng đồng điều trị tại Bệnh viện hữu nghị đa khoa tỉnh Nghệ An từ tháng 01/2021 đến tháng 04/2021. Kết quả: $60,0 \%$ số bệnh nhân đã sử dụng thuốc kháng sinh trước khi vào viện. $100 \%$ số bệnh nhân được sử dụng kháng sinh ngay khi vào viện: $82,4 \%$ dùng phác

* Dai hoc Y khoa Vinh

Chịu trách nhiệm chính: Nguyễn Văn Tuấn

Email: tuanminh1975@gmail.com

Ngày nhận bài: 14.6.2021

Ngày phản biên khoa học: 6.8.2021

Ngày duyệt bài: 16.8.2021
Nguyễn Văn Tuấn'

đồ đơn độc và 17,6\% được chỉ định phối hợp 2 loại kháng sinh ngay từ ban đầu. Phác đồ ban đầu: kháng sinh nhóm $\beta$-lactam được sử dụng nhiều nhất $(63,7 \%)$ : chủ yếu là Cephalosporin thế hệ $3(40 \%)$ và $\beta$-lactam/ức chế $\beta$ - lactamase $(21,2 \%)$. Trong quá trình điêu trị: có $32,8 \%$ phác đồ đơn độc ban đâu và 30,8\% phác đồ phối hợp 2 kháng sinh ban đâuu phải thay đổi phác đồ. Đa số bệnh nhân có thời gian sử dụng kháng sinh là $7-14$ ngày $(83,7 \%)$. Số ngày dùng kháng sinh trung bình là $9,48 \pm 3,02$ ngày. $35 \%$ phác đồ ban đẫu và 69,2\% phác đồ thay thế phù hợp với hướng dẫn điều trị của Bộ Y tế. Kết luận: Qua nghiên cứu trên bệnh nhân viêm phổi mắc phải cộng đồng cho thấy có một tỷ lệ cao bệnh nhân tự dùng kháng sinh trước khi nhập viện $(60,0 \%)$. Thời gian dùng kháng sinh trung bình là $9,48 \pm 3,02$ ngày; $35,0 \%$ phác đồ ban đâu và $69,2 \%$ phác đồ thay thế phù hợp với hướng đẫn điều trị của Bộ Y tế. Từ khóa: viêm phổi mắc phải cộng đồng, kháng sinh. 


\section{SUMMARY}

\section{STUDY ON THE CURRENT SITUATION OF} ANTIBIOTIC USE IN THE TREATMENT OF COMMUNITY-ACQUIRED PNEUMONIA AT NGHE AN FRIENDSHIP GENERAL HOSPITAL

Objective: To survey the situation of antibiotic use in the treatment of community-acquired pneumonia at Nghe An friendship general Hospital in 2021. Methods: A cross-sectional descriptive study was performed on 80 patients with communityacquired pneumonia who were treated at Nghe An Friendship General Hospital from January 2021 to April 2021. Results: $60,0 \%$ of patients had used antibiotics before entering the hospital. $100 \%$ of the patients were given antibiotics immediately upon admission: $82.4 \%$ were given a single regimen and $17.6 \%$ were prescribed a combination of 2 antibiotics. Initial regimen: The most commonly used antibiotics are $\beta$ lactam (63.7\%): 3rd generation Cephalosporins (40\%) and $\beta$-lactams/ $\beta$-lactamase inhibitors (21.2\%). During the treatment process: $32.8 \%$ of the initial monotherapy regimen and $30.8 \%$ of the initial 2 antibiotic combination regimen had to be changed. The duration of antibiotic use of the majority of patients was 7 - 14 days (83.7\%). The average number of days of antibiotic use was $9.48 \pm 3.02$ days. $35 \%$ of the initial regimen and $69.2 \%$ of the alternative regimen were consistent with the treatment guidelines of Vietnam's Ministry of Health.Conclusion: Through a study on patients with community-acquired pneumonia showed that a high percentage of patients self-administered antibiotics before hospital admission (60.0\%). The average number of days of antibiotic use was $9.48 \pm 3.02$ days. $35 \%$ of the initial regimen and $69.2 \%$ of the alternative regimen were consistent with the treatment guidelines of Vietnam's Ministry of Health.

Keywords; community-acquired pneumonia, antibiotics

\section{I. ĐĂT VẤN ĐỀ}

Nhiễm trùng đường hô hấp dưới là nguyên nhân đứng hàng thứ 3 tử vong toàn cầu và là nguyên nhân hàng đầu tử vong ở các nước kém phát triển. Viêm phổi mắc phải cộng đồng (VPMPCĐ) là một tình trạng nhiễm trùng đường hô hấp phổ biến trong cộng đồng. Viêm phổi đặc biệt đe dọa đến tính mạng của trẻ em dưới 5 tuổi, người già và những người bị các bệnh lý ảnh hưởng đến hệ thống miễn dịch nhưn đái tháo đường, HIV/AIDs, ... Kháng sinh (KS) là liệu pháp phổ biến nhất dùng trong điêu trị viêm phổi và hiệu quả của việc sử dụng kháng sinh cũng như tác dụng phụ của nó cũng thay đổi tùy từng đặc điểm của người bệnh [7]. Vấn đề lựa chọn và phối hợp kháng sinh ảnh hưởng lớn tới kết quả điều trị. Tuy nhiên, hiện nay với việc sử dụng kháng sinh ngày càng trở nên phổ biến và thiếu hợp lý đã dẫn tới che lấp các dấu hiệu lâm sàng, sai lệch kết quả xét nghiệm và gia tăng tỷ lệ kháng kháng sinh từ đó gây khó khăn trong việc điều trị. Tại Bệnh viện hữu nghị đa khoa Nghệ $A n$, đa số bệnh nhân VPMPCĐ đã được điêu trị từ tuyến huyện chuyển đênn, một số khác đã tự dùng kháng sinh trước đó nên tính chất bệnh đã thay đổi và quá trình xét nghiệm xác định căn nguyên bệnh cũng gặp khó khăn. Do đó, một lượng lớn bệnh nhân được điều trị dựa theo kinh nghiệm. Chính vì vậy, việc đánh giá tình hình sử dụng kháng sinh tại bệnh viện là cơ sở để định hướng mô hình bệnh, mô hình vì khuẩn, từ đó có sự lựa chọn và sử dụng kháng sinh hợp lý nhằm nâng cao hiệu quả, giảm giá thành và hạn chế sự phát triển lan tràn của các chủng vi khuẩn kháng thuốc. Xuất phát từ thực tế đó chúng tôi tiến hành nghiên cứu đề tài này với mục tiêu: Khảo sát tình hinh sử dụng kháng sinh trong điều trị viêm phổi mắc phải ở cộng đồng tại Bệnh viện Hữu Nghị Đa Khoa Nghệ An năm 2021.

\section{II. ĐỐI TƯỢNG VÀ PHƯƠNG PHÁP NGHIÊN CỨU}

1. Đối tượng nghiên cứu. Bệnh nhân được chẩn đoán viểm phổi mắc phải cộng đồng điều trị tại Bệnh viện Hữu Nghị Đa khoa Nghệ An.

\subsection{Tiêu chuẩn lựa chọn}

- Bệnh nhân được chẩn đoán viêm phổi mắc phải cộng đồng theo "Hướng dẫn chẩn đoán và điều trị viêm phổi mắc phải cộng đồng ở người lớn" của Bộ Y tễ năm 2020 [1].

- Bệnh nhân đồng ý tham gia nghiên cứu.

\subsection{Tiêu chuẩn loại trừ}

- Bệnh nhân dưới 16 tuổi, bệnh nhân không tuân thủ điều trị.

- Bệnh nhân VPMPCĐ kèm theo lao phổi hoặc có suy giảm miễn dịch nặng hoặc đang mắc bệnh nhiễm khuẩn ở các bộ bộ phận khác kèm theo.

\section{Phương pháp nghiên cứu}

2.1. Địa điểm và thời gian nghiên cứu

- Địa điểm nghiên cứu: Bệnh viện Hữu nghị đa khoa Nghệ An.

- Thời gian nghiên cứu: Từ 01/2021 đến 04/2021.

2.2. Thiết kế nghiên cứu: Nghiên cứu mô tả cắt ngang có phân tích

\subsection{Cõ̃ mẫu và phương pháp chọn mẫu}

- Cõ mẫu: 80 bệnh nhân

- Phương pháp chọn mẫu: Chọn mẫu thuận tiện, lựa chọn tất cả bệnh nhân đáp ứng tiều chuẩn lựa chọn và tiêu chuẩn loại trừ trong thời gian nghiên cứu.

2.4. Các tiêu chuẩn áp dụng trong nghiên cứu

2.4.1. Tiêu chuẩn đánh giá mức độ nặng của 
bệnh VPMPCĐ. Đánh giá mức độ nặng nhẹ, chỉ định điều trị nội ngoại trú dựa theo thang điểm CURB65 [1]: C: Rối loạn ý thức; U: Ure > $7 \mathrm{mmol} / \mathrm{L} ; \mathbf{R}$ : Tần số thở $\geq 30$ lần/ phút; $\mathbf{B}$ : Huyết áp: Huyết áp tâm thu $<90 \mathrm{mmHg}$ hoặc huyết áp tâm trương $\leq 60 \mathrm{mmHg} ; 65$ : tuổi: $\geq 65$

Mỗi biểu hiện trên được tính 1 điểm, tính tổng số điểm và đánh giá: Viêm phổi nhẹ: CURB65 $=0$ - 1 điểm: Có thể điêu trị ngoại trú; Viêm phổi trung bình: CURB65 = 2 điểm: Điêu trị tại các khoa nội; Viêm phổi nặng: CURB65 = 3 - 5 điểm: Điều trị tại khoa, trung tâm hô hấp, ICU.

2.4.2. Đánh giá về lựa chọn phác đồ kháng sinh theo kinh nghiệm. Đánh giá phác đồ KS sử dụng theo hai trường hợp:

- Phác đồ phù hợp khuyến cáo: nếu đúng tiêu chuẩn nhập khoa, đúng phác đồ về số lượng thuốc trong phác đồ, đúng nhóm thuốc và đúng loại thuốc theo mức độ nặng của bệnh theo hướng đãn điều trị chuẩn của Bộ Y tế Việt Nam đưa ra năm 2020 [1] và IDSA/ATS năm 2007 [6].

- Phác đồ không phù hợp với khuyến cáo: Những trường hợp khác.

\subsection{3. Đánh giá hiệu quả điều trị}

Hiệu quả điều trị đánh giá dựa theo kết luận của bác sĩ khi tổng kết bệnh án.

Khỏi hoàn toàn: hết các triệu chứng lâm sàng; Đõ̃-giảm: Các triệu chứng lâm sàng thuyên giảm, bệnh nhân có thể điểu trị ngoại trú; Chuyển ICU hoặc tuyến trên: tình trạng bệnh nhân không được cải thiện, hoặc tình trạng bệnh nhân có chiều hướng xấu đi; Tử vong.

Kết luận: Thành công: bệnh nhân khỏi hoàn toàn hoặc đõ - giảm; Không thành công: bệnh nhân chuyển ICU hoặc tuyến trên hoăc tử vong.

2.4.4. Đánh giá lý do thay đổi phác đồ điều trị

Không đáp ứng: các triệu chứng lâm sàng và cận lâm sàng không cải thiện sau điều trị; Nặng lên: Các triệu chứng lâm sàng và cận lâm sàng tăng lên so với lúc vào viện, có xu hướng tiến triển xấu; Theo KS đồ: Tìm được vi khuẩn trong bệnh phẩm xét nghiệm và làm KS đồ.

2.5. Phương pháp xử lý số liệu: - Số liệu được xử lý bằng phần mềm SPSS 20.0.

- Sử dụng test X2 để so sánh sự khác biệt về tỷ lệ phần trăm.

- Sự khác biệt có ý nghĩa thống kê khi p < 0,05.

\section{KẾT QUẢ NGHIÊN CỨU}

Bảng 1. Tình hình sử dung kháng sinh trước vào viện cảu đôí tượng nghiên cứu

\begin{tabular}{|c|c|c|c|c|}
\hline \multirow[b]{2}{*}{ Tiêu chí } & \multicolumn{3}{|c|}{ Mức độ VPMPCĐ } & \multirow[b]{2}{*}{ Tổng } \\
\hline & $\begin{array}{c}\text { Nhe } \\
n=11\end{array}$ & $\begin{array}{l}\text { Trung } \\
\text { bình } \\
n=47\end{array}$ & $\begin{array}{l}\text { Năng } \\
n=22\end{array}$ & \\
\hline $\begin{array}{l}\text { Có dùng } \\
\text { KS }\end{array}$ & $\begin{array}{c}9 \\
(81,8 \%)\end{array}$ & $\begin{array}{c}24 \\
(51,1 \%)\end{array}$ & $\begin{array}{c}15 \\
(68,2 \%)\end{array}$ & $\begin{array}{c}48 \\
(60 \%)\end{array}$ \\
\hline $\begin{array}{l}\text { Không } \\
\text { dùng KS }\end{array}$ & $\begin{array}{c}2 \\
(18,2 \%)\end{array}$ & $\begin{array}{c}23 \\
(48,9 \%) \\
\end{array}$ & $\begin{array}{c}7 \\
(31,8 \%)\end{array}$ & $\begin{array}{c}32 \\
(40 \%)\end{array}$ \\
\hline
\end{tabular}

Nhận xét: Tỷ lệ BN đã sữ dụng thuốc KS trước khi vào viện ở mức cao $(60 \%)$.

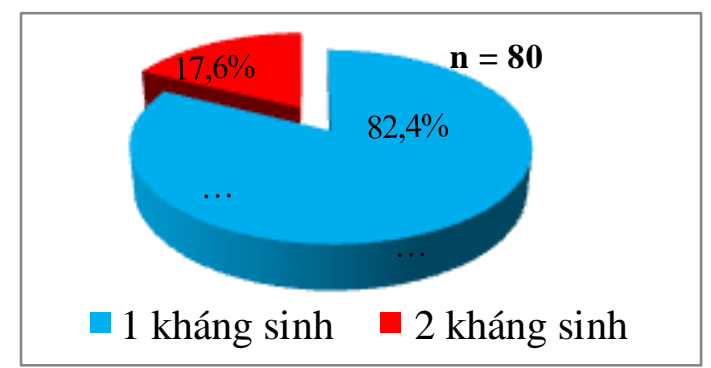

Biểu đồ 1. Kiểu phác đồ sư dụng kháng sinh ban đầu trong điều trị của đôi tượng nghiên cứu

Nhân xét: $100 \%$ được sử dụng KS ngay khi vào viện: $82,4 \%$ dùng phác đồ đơn độc và 17,6\% được chỉ định phối hợp 2 loại KS ngay từ ban đầu.

Bảng 2. Các kiểu phác đồ kháng sinh ban đâu theo kinh nghiệm cảu đối tượng nghiên cứu

\begin{tabular}{|c|c|c|c|c|c|c|c|c|}
\hline \multirow{3}{*}{ Phác đồ KS } & \multicolumn{6}{|c|}{ Mức độ VPMPCĐ } & \multirow{2}{*}{\multicolumn{2}{|c|}{ Tổng }} \\
\hline & \multicolumn{2}{|c|}{ Nhe $(n=11)$} & \multicolumn{2}{|c|}{ Trung bình $(n=47)$} & \multicolumn{2}{|c|}{ Năng (n=22) } & & \\
\hline & $\mathbf{n}$ & $\%$ & $n$ & $\%$ & $n$ & $\%$ & $\mathbf{n}$ & $\%$ \\
\hline \multicolumn{9}{|c|}{ Phác đồ đơn độc } \\
\hline $\begin{array}{c}\beta \text {-lactam / ức chế } \\
\beta \text {-lactamase }\end{array}$ & 5 & 45,5 & 11 & 23,4 & 1 & 4,5 & 17 & 21,2 \\
\hline C3G & 5 & 45,5 & 22 & 46,8 & 5 & 22,7 & 32 & 40 \\
\hline Quinolon & 1 & 9,0 & 9 & 19,1 & 5 & 22,7 & 15 & 18,7 \\
\hline $\begin{array}{l}\beta \text {-lactam chống } \\
\text { Pseudomonas }\end{array}$ & 0 & 0 & 0 & 0 & 2 & 9,1 & 2 & 2,5 \\
\hline Tống & 11 & 100 & 42 & 89,3 & 13 & 59,0 & 66 & 82,4 \\
\hline \multicolumn{9}{|c|}{ Phác đồ phối hợp } \\
\hline $\begin{array}{c}\beta \text {-lactam/ức chế } \beta \text { - } \\
\text { lactamase +Quinolon }\end{array}$ & 0 & 0 & 2 & 4,3 & 1 & 4,5 & 3 & 3,8 \\
\hline
\end{tabular}




\begin{tabular}{|c|c|c|c|c|c|c|c|c|}
\hline C3G + Quinolon & 0 & 0 & 2 & 4,3 & 6 & 27,4 & 8 & 10 \\
\hline $\begin{array}{c}\text { Quinolon + ß-lactam } \\
\text { chống Pseudomonas }\end{array}$ & 0 & 0 & 1 & 2,1 & 2 & 9,1 & 3 & 3,8 \\
\hline Tống & 0 & 0 & 5 & 10,7 & 9 & 41,0 & 14 & 17,6 \\
\hline
\end{tabular}

Nhân xét: KS nhóm $\beta$-lactam được sử dụng nhiều nhất $(63,7 \%)$ : chủ yếu C3G (40\%), $\beta$ lactam/ức chế $\beta$ - lactamase (21,2\%). Phác đồ phối hợp được chỉ định trong 17,6\% trường hợp.

Bảng 3. Thay đổi phác đồ theo kinh nghiệm của đối tượng nghiên cứu

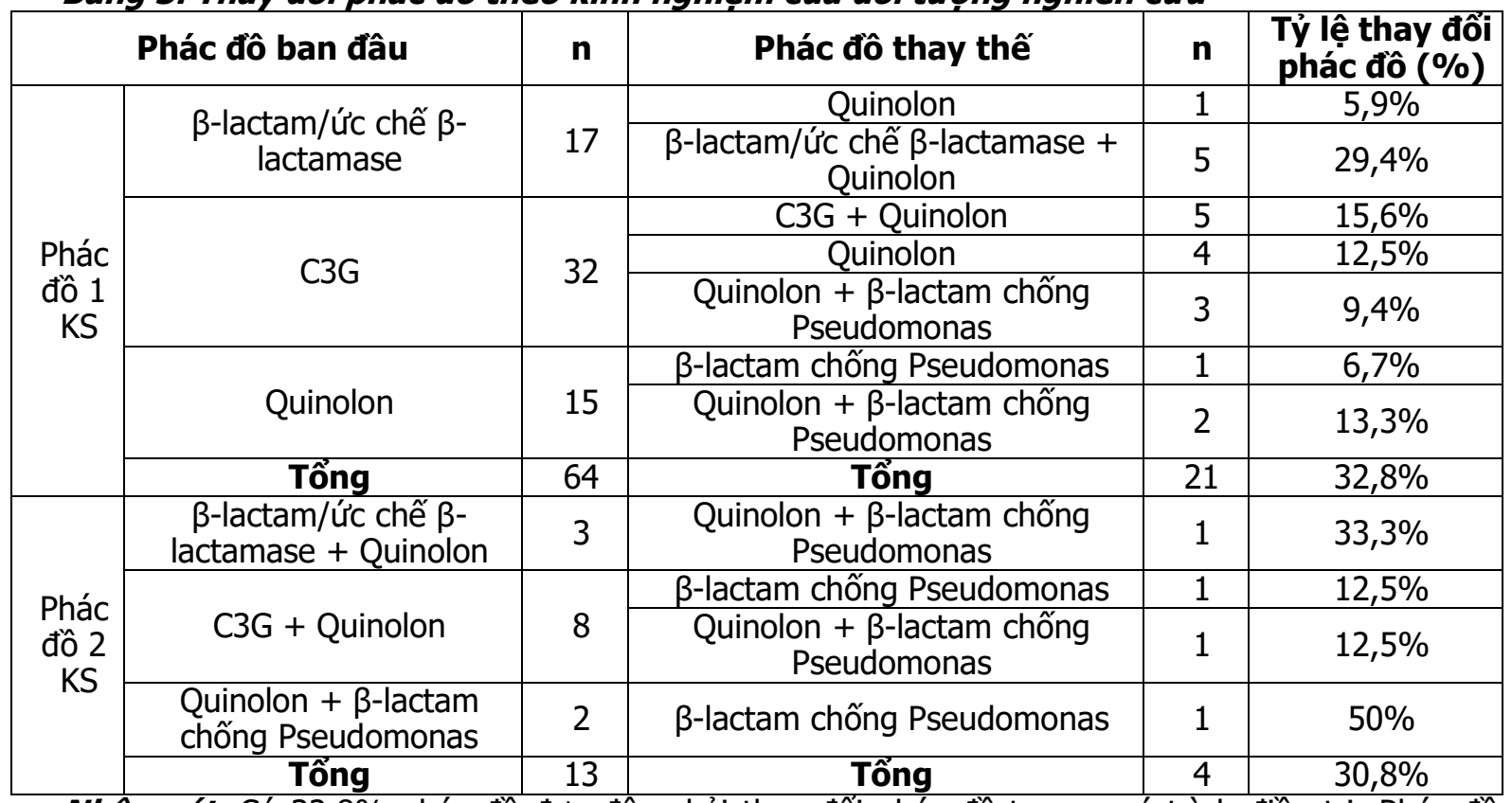

Nhân xét: Có 32,8\% phác đồ đơn độc phải thay đổi phác đồ trong quá trình điều trị. Phác đồ phối hợp 2 KS có 30,8\% trường hợp có sự thay đổi phác đồ.

Bảing 4. Đánh giá tính hợp của các phác đổ so với hướng dẫn của ATS và Bộ Y tế

\begin{tabular}{|c|c|c|c|c|c|c|c|c|}
\hline \multirow{3}{*}{$\begin{array}{l}\text { Phác đồ } \\
\text { đîêu trị }\end{array}$} & \multicolumn{6}{|c|}{ Mức độ VPMPCD } & \multirow{2}{*}{\multicolumn{2}{|c|}{ Tổng }} \\
\hline & \multicolumn{2}{|c|}{ Nhe $(n=11)$} & \multicolumn{2}{|c|}{ Trung bình $(n=47)$} & \multicolumn{2}{|c|}{ Năng (n=22) } & & \\
\hline & $\begin{array}{c}\text { ATS } \\
(n, \%)\end{array}$ & $\begin{array}{c}\text { BYT } \\
(n, \%)\end{array}$ & $\begin{array}{c}\text { ATS } \\
(n, \%)\end{array}$ & $\begin{array}{c}\text { BYT } \\
(n, \%)\end{array}$ & $\begin{array}{c}\text { ATS } \\
(n, \%)\end{array}$ & $\begin{array}{c}\text { BYT } \\
(n, \%)\end{array}$ & $\begin{array}{c}\text { ATS } \\
(n, \%)\end{array}$ & $\begin{array}{c}\text { BYT } \\
(n, \%)\end{array}$ \\
\hline \multicolumn{9}{|c|}{ Phác đồ ban đầu } \\
\hline Phù hợp & $\begin{array}{c}1 \\
9,1 \%\end{array}$ & $\begin{array}{c}6 \\
54,5 \%\end{array}$ & $\begin{array}{c}9 \\
19,1 \%\end{array}$ & $\begin{array}{c}13 \\
27,7 \%\end{array}$ & $\begin{array}{c}10 \\
45,5 \%\end{array}$ & $\begin{array}{c}9 \\
40,9 \%\end{array}$ & $\begin{array}{c}20 \\
25 \%\end{array}$ & $\begin{array}{c}28 \\
35 \%\end{array}$ \\
\hline $\begin{array}{l}\text { Không } \\
\text { phù hợp }\end{array}$ & $\begin{array}{c}10 \\
90,9 \%\end{array}$ & $\begin{array}{c}5 \\
45,5 \%\end{array}$ & $\begin{array}{c}38 \\
80,9 \%\end{array}$ & $\begin{array}{c}34 \\
72,3 \%\end{array}$ & $\begin{array}{c}12 \\
54,5 \%\end{array}$ & $\begin{array}{c}13 \\
59,1 \%\end{array}$ & $\begin{array}{c}60 \\
75 \%\end{array}$ & $\begin{array}{c}52 \\
65 \%\end{array}$ \\
\hline \multicolumn{9}{|c|}{ Phác đố thay thế } \\
\hline Phù hợp & $\begin{array}{c}2 \\
40 \%\end{array}$ & $\begin{array}{c}2 \\
40 \%\end{array}$ & $\begin{array}{c}2 \\
18,2 \%\end{array}$ & $\begin{array}{c}10 \\
100 \%\end{array}$ & $\begin{array}{c}7 \\
70 \%\end{array}$ & $\begin{array}{c}6 \\
60 \%\end{array}$ & $\begin{array}{c}11 \\
42,3 \%\end{array}$ & $\begin{array}{c}18 \\
69,2 \%\end{array}$ \\
\hline $\begin{array}{l}\text { Không } \\
\text { phù hợp }\end{array}$ & $\begin{array}{c}3 \\
60 \%\end{array}$ & $\begin{array}{c}3 \\
60 \%\end{array}$ & $\begin{array}{c}9 \\
81,8 \%\end{array}$ & $\begin{array}{c}0 \\
0 \%\end{array}$ & $\begin{array}{c}3 \\
30 \%\end{array}$ & $\begin{array}{c}4 \\
40 \% \\
\end{array}$ & $\begin{array}{c}14 \\
57,7 \%\end{array}$ & $\begin{array}{c}7 \\
30,8 \%\end{array}$ \\
\hline
\end{tabular}

Nhận xét: Tỷ lệ các phác đồ ban đâuu phù hợp với các hướng dấn điều trị tương đối thấp: $25 \%$ với khuyến cáo của ATS, $35 \%$ với khuyến cáo của Bộ Y tế. Nhóm bệnh nhân nặng có tỷ lệ phù hợp với các khuyến cáo cao hơn.

Bảng 5. Thởi gian sử dụng kháng sinh của đôí tượng nghiên cứu

\begin{tabular}{|c|c|c|}
\hline Thời gian & $\mathbf{n}$ & Tỷ lệ \\
\hline $3-6$ ngày & 8 & $10 \%$ \\
\hline $7-14$ ngày & 67 & $83,7 \%$ \\
\hline$>14$ ngày & 5 & $6,3 \%$ \\
\hline Trung bình (M.SD) & $9,48 \pm 3,02$ \\
\hline
\end{tabular}

Nhận xét: Đa số bệnh nhân có thời gian sử dụng KS là 7-14 ngày (83,7\%). Số ngày dùng KS 
trung bình là $9,48 \pm 3,02$ ngày.

Bảng 6. Kết quả điều trị của đôi tượng nghiên cứu

\begin{tabular}{|c|c|c|c|c|c|c|c|c|}
\hline \multirow{3}{*}{ Kết quả } & \multicolumn{6}{|c|}{ Mức độ VPMPCĐ } & \multirow{2}{*}{\multicolumn{2}{|c|}{ Tổng }} \\
\hline & \multicolumn{2}{|c|}{ Nhe $(n=11)$} & \multicolumn{2}{|c|}{ Trung bình $(n=47)$} & \multicolumn{2}{|c|}{ Nặng (n=22) } & & \\
\hline & $\mathbf{n}$ & $\%$ & n & $\%$ & n & $\%$ & $\mathbf{n}$ & $\%$ \\
\hline Khỏi & 6 & 54,5 & 9 & 19,2 & 1 & 4,5 & 16 & 20 \\
\hline Đõ - giảm & 4 & 36,4 & 37 & 78,7 & 17 & 77,3 & 58 & 72,5 \\
\hline Chuyến ICU hặc tuyến trên & 1 & 9,1 & 1 & 2,1 & 4 & 18,2 & 6 & 7,5 \\
\hline
\end{tabular}

Nhận xét: Tỷ lệ bệnh nhân được điều trị thành công là $92,5 \%$, trong đó tỷ lệ bệnh nhân khỏi là $20 \%$, đõ̃-giảm là $72,5 \%$. Có $6 / 80$ bệnh nhân không điều trị thành công chiếm $7,5 \%$. Không có bệnh nhân tử vong.

Bảng 7. Môi tương quan giứa phác đồ kháng sinh và kêt quả điều trị của đôî tượng nghiên cứu

\begin{tabular}{|c|c|c|c|c|c|c|c|}
\hline \multirow{3}{*}{ Phác đồ } & \multicolumn{6}{|c|}{ Kết quả điều trị } & \multirow{3}{*}{$\mathbf{p}$} \\
\hline & \multicolumn{2}{|c|}{ Khỏi } & \multicolumn{2}{|c|}{ Đõ - giảm } & \multicolumn{2}{|c|}{$\begin{array}{c}\text { Chuyến ICU } \\
\text { hoặc tuyến trên }\end{array}$} & \\
\hline & $\mathbf{n}$ & $\%$ & $\mathbf{n}$ & $\%$ & n & $\%$ & \\
\hline$\beta$-lactam/ức chế $\beta$-lactamase & 6 & 37,5 & 11 & 25 & 0 & 0 & \\
\hline C3G & 7 & 43,7 & 23 & 52,3 & 2 & 50 & \\
\hline Quinolon & 3 & 18,8 & 10 & 22,7 & 2 & 50 & 0500 \\
\hline Tống & 16 & 100 & 44 & 100 & 4 & 100 & \\
\hline
\end{tabular}

Nhận xét: Với phác đồ C3G, tỷ lệ bệnh nhân khỏi, đõ - giảm cao hơn phác đồ $\beta$-lactam/ức chế $\beta$ lactamase và phác đồ Quinolon, tuy nhiển sự khác biệt không có ý nghĩa thống kê $(p>0,05)$.

\section{BÀN LUÂNN}

Danh mục các kháng sinh sử dụng điêu trị viêm phổi mắc phải cộng đồng: Có $60 \%$ bểnh nhân trong mẫu nghiên cứu có sử dụng KS trước vào viện, có nhiều nhóm KS khác nhau đã được sử dụng, trong đó có tới $75 \%$ số bệnh nhẩn không nhớ hoặc không biết mình đã sử dụng thuốc KS loại nào. Điều này cho thấy rõ thực trạng việc mua bán và sử dụng KS trong cộng đồng rất phổ biến và chưa được kiểm soát chặt chẽ. Vấn đề này đã gây không ít khó khăn cho các bác sỹ trong việc đánh giá mức độ bệnh và lựa chọn KS theo kinh nghiệm do không thể thu thập hết được tiền sử dùng thuốc. Toàn bộ bệnh nhân được chẩn đoán VPMPCĐ trong mẫu nghiên cứu đều được chỉ định KS ngay từ đầu. Trong đó có $82,4 \%$ bệnh nhân được chỉ định phác đồ đợn độc. Kết quả này cao hơn nghiên cứu của Đố Trung Nghĩa là $63,1 \%$ [3] và nghiên cứu của MI. Costa và cộng sự (2020) với 42,8\% lượt chỉ định phác đồ đớn độc [5].

Với phác đồ đơn độc: Kháng sinh nhóm $\beta$-lactam được sử dụng nhiều nhất, chiếm $61,2 \%$ số lượt chỉ định, trong đó chủ yếu C3G (40\%), $\beta$ lactam + ức chế $\beta$ - lactamase $(21,2 \%)$. Kết quả này tương đồng với kết quả nghiên cứu của Đỗ Trung Nghĩa tại tỉnh Thái Nguyên năm 2017 với $59,5 \%$ lượt chỉ định nhóm $\beta$-lactam, trong đó $36,1 \%$ là PĐ C3G [3] và kết quả của Nguyễn Thị Hương tại khoa nội - Bệnh viện Đa Khoa tỉnh Quảng Trị năm 2013 với 55,4\% lượt chỉ định KS nhóm $\beta$-lactam, trong đó chủ yếu là C3G $(36,3 \%)$ [2]. Ở nước ta một số vi khuẩn thường gây viêm phổi như: S.Pneumoniae, H. Influenzae, Klebsiella pneumoniae... ngoài ra thủ phạm gây viêm phổi không điển hình thường là Mycoplasma pneumoniae. Do đó, 3 nhóm KS được các khuyên cáo lựa chon đầu tiên là $\beta$ - lactam, macrolid và aminosid. Vì vậy việc sử dụng một tỷ lệ lớn $\beta$ lactam + ức chế $\beta$ - lactamase và C3G là có cơ sở. Nhóm fluoroquinolon được sử dụng với $18,7 \%$ sỗ lượt chỉ định, trong đó moxifloxacin được sử dụng chủ yếu. Việc sử dụng KS nhóm quinolon cho bệnh lý đường hô hấp cũng được ghi rõ trong hướng dẫn điều trị của Bộ Y tế cho cả 3 mức độ VPMPCD [1].

Với phác đồ phối hợp: Có 17,6\% lượt chî định phác đồ phối hợp 2 loại KS. Trong đó chủ yếu là nhóm $\beta$-lactam kết hợp với 1 nhóm KS khác, cụ thể: $\beta$-lactam + quinolon (13,8\%) được chỉ định trên $B N$ viêm phổi trung bình và nặng; Quinolon $+\beta$-lactam chống Pseudomonas được chỉ định $3 / 80$ BN $(3,8 \%)$. Nghiên cứu của Đỗ Trung Nghĩa với 100\% phác đồ phối hợp 2 KS là $1 \beta$-lactam kết hợp với 1 nhóm KS khác [3]. Sự thay đổi phác đồ kháng theo kinh nghiệm dựa trên đáp ứng lâm sàng của bệnh nhân.

Kết quả nghiên cứu của chúng tôi cho thấy $32,8 \%$ phác đồ đơn độc được thay đổi phác đồ trong quá trình điều trị. Trong đó chủ yếu là thay đổi từ nhóm $\beta$-lactam sang quinolon hoặc kết hợp $\beta$-lactam với quinolon để tăng tác dụng diệt 
khuẩn, tăng phổ tác dụng lên VK Gram (-). Việc thay đổi phác đồ phụ thuộc vào đáp ứng lâm sàng của bệnh nhân, trong trường hợp bệnh nhân dị ứng $K S$, tiến triển chậm hoặc tiến triển nặng lên.... các bác sỹ cần hội chẩn để đưa ra phác đồ mới phù hợp hơn.

Về tính phù hợp của việc sử dụng kháng sinh. Với phác đồ ban đầu: Nghiển cứu lấy hướng dẫn điều trị của Bô $Y$ tế ban hành năm 2020 và IDSA/ATS năm 2007 về lựa chọn KS cho VPMPCĐ làm tiêu chuẩn phân tích [1],[6]. Mức độ nặng của bệnh theo CURB65 là tiêu chuẩn để lựa chọn phác đồ. Kết quả nghiên cứu cho thây chỉ có tổng cộng 28 phác đồ (35\%) phù hợp với hướng dẫn điều trị của BYT và 20/80 (25\%) phác đồ phù hợp với ATS. Các nguyên nhân dẫn đến không phù hợp với phác đồ khuyến cáo bao gồm: Phác ban đầu lựa chọn theo kinh nghiệm; Độ nhạy của các KS sử dụng với mô hình vi khuẩn thường gặp; Giới hạn các loại thuốc của kho dược bênh viện. So với nghiên cứu của các tác giả Nguyễn Thị Hương ( $9 \%)$, Đỗ Trung Nghĩa $(25,8 \%)$ tỷ lệ phù hợp so với khuyến cáo của Bộ Y tế trong nghiên cứu chúng tôi cao hơn (35\%) do có sự quan tâm công tác dược lâm sàng, thường xuyên giám sát điều trị, cập nhật, đào tạo các hướng dẫn điều trị để đảm bảo sử dụng thuốc an toàn, hiệu quả, hợp lý trên bệnh nhân.

Với phác đồ thay thế: Trong tổng số 25 bênh nhân được thay đổi phác đồ thì có $69,2 \%$ phác đồ thay thế phù hợp với hướng dẫn điêu trị của Bộ $Y$ tế và $42,3 \%$ phù hợp với khuyến cáo của ATS. Có sự cải thiện trong việc áp dụng các khuyến cáo điều trị có thể là do sau khi đã có sự đánh giá và theo dõi đáp ứng của bệnh nhân, các bác sỹ đã nhìn nhận chính xác hớn về mức độ bệnh của bệnh nhân, hội chẩn với đồng nghiệp và lãnh đạo khoa để đưa phác đồ hợp lý nhất cho bênh nhân.

Về thời gian sử dụng kháng sinh: Trong nghiên cứu của chúng tổi thời gian bệnh nhân sử dụng kháng sinh trung bình là 9,48 $\pm 3,02$ ngày. Nghiên cứu của Nguyển Thị Hương năm 2013 tại Bệnh viện đa khoa Quảng trị thì thời gian này là $9,81 \pm 0,38$ ngày [2] và trong một nghiên cứu đa trung tâm của $S$. Aliberti và cộng sự từ năm 2001 đến 2005 cho thấy thời gian sử dụng kháng sinh trung bình trong điều trị VPMPCĐ là $11 \pm$ 4,7 ngày, trong đó $42 \%$ có thời gian dùng kháng sinh từ 10 - 14 ngày, $39 \%$ có thời gian dùng kháng sinh $<10$ ngày và $19 \%$ có thời gian dùng kháng sinh > 14 ngày [4]. Trong nghiên cứu của chúng tôi, đa số bệnh nhân sử dụng KS từ 7-14 ngày $(83,7 \%)$, thời gian sử dụng $\mathrm{KS}$ này phù hợp với khuyến cáo của Bộ Y tế trong tài liệu hướng dẫn sử dụng KS năm 2015.

Về hiệu quả điều trị được đánh giá trên các cơ sở các theo dõi lâm sàng và trên một số xét nghiệm. Trong nghiên cứu cho thấy số bệnh nhân khỏi chiếm tỷ lệ $20 \%$ tương đương với 16 bệnh nhân khỏi hẳn, đõ là $72,5 \%$, chuyển ICU hoặc tuyến trên $7,5 \%$ do không cải thiện hoặc có chiều hướng xấu đi, không có bệnh nhân tử vong. Kết quả nghiên cứu này có sự tương đồng với các kết quả nghiên cứu của Đố Trung Nghĩa năm 2013 ở bênh viện $A$ tỉnh Thái Nguyên với $94,9 \%$ bệnh nhân khỏi và đõ, trong đó $92,3 \%$ bệnh nhân đõ [3].

\section{KẾT LUÂN}

Qua nghiên cứu trên bệnh nhân viêm phổi mắc phải cộng đồng cho thấy có một tỷ lệ cao bệnh nhân tự dùng kháng sinh trước khi nhập viện $(60 \%)$. Thời gian dùng kháng sinh trung bình là $9,48 \pm 3,02$ ngày; $35,0 \%$ phác đồ ban đầu và $69,2 \%$ phác đồ thay thế phù hợp với hướng đẫn điều trị của Bộ Y tế.

\section{TÀI LIÊU THAM KHẢO}

1. Bộ Y Tế (2020), "Hướng dẫn chẩn đoán và điều trị viêm phổi mắc phải cộng đồng ở người lớn", tr. 7-45.

2. Nguyễn Thi Hương (2013), "Đánh giá tình hình sử dụng kháng sinh trong điều trị viêm phổi mắc phải ở cộng đồng tại khoa Nội- Bệnh viện đa khoa Qưảng Trị", Đại học Dược Hà Nôii.

3. Đố Trung Nghĩa (2017), "Phần tích tình hình sử dung KS trong điêu tri viêm phổi mắc phải công đồng tại Bệnh viện A tỉnh Thái Nguyên", Đại học Dược Hà Nội; 2017.

4. Aliberti S, Blasi $F$, Zanaboni AM, Peyrani $\mathbf{P}$, Tarsia P, Gaito S, et al (2010), "Duration of antibiotic therapy in hospitalised patients with community-acquired pneumonia", Eur Respir J. ; 36(1):128-34.

5. Costa MI, Cipriano A, Santos F V, Valdoleiros SR, Furtado I, Machado A, et al (2020), "Clinical profile and microbiological aetiology diagnosis in adult patients hospitalized with community-acquired pneumonia", Pulmonology. 2020 Dec.

6. Mandell LA, Wunderink RG, Anzueto A, Bartlett JG, Campbell GD, Dean NC, et al (2007), "Infectious Diseases Society of America/American Thoracic Society Consensus Guidelines on the management of community-acquired pneumonia in adults. Clin Infect Dis"; 44(SUPPL. 2).

7. Rivero-Calle I, Pardo-Seco J, Aldaz P, Vargas DA, Mascarós E, Redondo E, et al (2016), "Incidence and risk factor prevalence of community-acquired pneumonia in adults in primary care in Spain (NEUMO-ES-RISK project)", BMC Infect Dis [Internet];16(1):1-8. 